\title{
Impact of mechanical heterogeneity on joint density in a welded ignimbrite
}

2 A.M. Soden*, R.J. Lunn ${ }^{1}$ and Z.K. Shipton ${ }^{1}$

3 School of Geographical and Earth Sciences, University of Glasgow, Glasgow, G12 8QQ, UK

${ }^{1}$ Department of Civil \& Environmental Engineering, University of Strathclyde, Glasgow, G1 1XJ, UK

\section{Abstract}

Joints are conduits for groundwater, hydrocarbons and hydrothermal fluids. Robust fluid flow models rely on accurate characterisation of joint networks, in particular joint density. It is generally assumed that the predominant factor controlling joint density in layered stratigraphy is the thickness of the mechanical layer where the joints occur. Mechanical heterogeneity within the layer is considered a lesser influence on joint formation. We analysed the frequency and distribution of joints within a single 12-meter thick ignimbrite layer to identify the controls on joint geometry and distribution. The observed joint distribution is not related to the thickness of the ignimbrite layer. Rather, joint initiation, propagation and termination are controlled by the shape, spatial distribution and mechanical properties of fiamme, which are present within the ignimbrite. The observations and analysis presented here demonstrate that models of joint distribution, particularly in thicker layers, that do not fully account for mechanical heterogeneity are likely to underestimate joint density, the spatial variability of joint distribution and the complex joint geometries that result. Consequently, we recommend that characterisation of a layer's compositional and material properties improves predictions of subsurface joint density in rock layers that are mechanically heterogeneous.

\section{Introduction}

The accurate characterisation of fracture attributes is essential for constraining fracture network models and, as a consequence, for improving predictions of fluid flow in fractured rocks. Such flow predictions can be key to assessing the viability of individual sites for industrial production, as for example, in assessing aquifer recharge for groundwater production schemes (Neuman, 2005; JimenezMartinez et al., 2013), determining the viability of enhanced geothermal systems (Fox et al., 2013; Hofmann et al., 2014) and determining hydrocarbon production prospects in tight reservoirs (Koning, 2003). Stochastic or mechanical models that predict fracture distribution and geometry at depth are more reliable if they include information and interpretations about the manner in which fracture initiation, growth and arrest are affected by variables such as rock strength, anisotropy, stress state and fluid pressure (Cacas et al., 2001). 
Predictive models of joint density generally focus on the thickness of the jointing layer, as commonly observed in layered sedimentary rocks where opening-mode joints occur as laterally persistent, layerconfined, parallel sets, with a positive correlation between median joint spacing and mechanical layer thickness. (Huang and Angelier, 1989, Narr and Suppe, 1991; Gross, 1993; Ji and Saruwatari, 1998; Ji et al., 1998; Fisher and Polansky, 2006). However, factors other than layer thickness also affect the number and geometry of joints within a layer. Principal among these is the mechanical heterogeneity of the layer, that is a factor overlooked in many numerical models of joint formation, which apply only to isotropic, homogeneous layers. In reality, rocks are spatially heterogeneous, varying in both composition and mechanical properties. Several workers have shown that mechanical heterogeneities in the form of flaws or inclusions are sites of joint initiation in rock. Inclusions such as fossils and intraclasts and flaws in the form of pores, bed forms and microcracks (Pollard and Aydin, 1988; Gross, 1993; McConaughy and Engelder, 2001; Weinberger, 2001a) perturb the regional stress field and act to concentrate stress at the flaw until it exceeds the tensile strength of the rock, promoting joint initiation and propagation. When an inclusion is weaker than the surrounding rock, the stress concentration is tangential to the inclusion, for stronger inclusions the tensile stress is greater within the inclusion and the tangential stress less (Pollard and Aydin, 1988). Futhermore, inclusions can localise stress at the greatest point of curvature i.e. at 'corners' or 'tips' (Eshelby, 1957, 1959; Pollard and Aydin, 1988). Hence, flaw distribution, size, shape and material properties affect the density, average spacing and saturation of joints in a rock layer (Weinberger, 2001b; Tuckwell et al., 2003)

Mechanical heterogeneity not only controls joint initiation and propagation but also impacts joint geometry. In homogeneous material, joint propagation is proposed to occur by coalescing of microcracks in the process zone ahead of the joint tip (Scholz, 1993) resulting in planar joints. By contrast, observations of joints at sedimentary interfaces show that joints can step across, bifurcate or propagate straight through them (Cooke and Underwood, 2001; Larsen et al., 2010). Numerical modelling of this process demonstrates that as a fracture tip approaches an interface, two stress maxima occur ahead and either side of the fracture tip (Cooke and Underwood, 2001) resulting in a step-wise propagation of the joint, rather than a simple continuing coalescence for a migrating process zone.

In this study, we examine the manner in which the spatial distribution and geometry of joints in a 12 meter thick densely welded ignimbrite layer are affected by the geometrical and mechanical characteristics of heterogeneities in the form of fiamme, which create mechanical heterogeneities within the lithology. Although layering has been shown to play a significant role in the spatial distribution of joints; in the absence of strong layering, mechanical heterogeneity within, may exert a strong influence on joint network development. Our study is an example of how spatially 
heterogeneous rock strength impacts joint development and the properties of the resultant joint network.

The observations and analysis presented here demonstrate that models of joint distribution, particularly in thicker layers, that do not fully account for mechanical heterogeneity are likely to underestimate joint density, the spatial variability of joint distribution and the complex joint geometries that result. Our observations may also serve as an analogue for understanding the affect mechanical heterogeneities can have on joint networks in layered sedimentary sequences.

\section{Formation and properties of ignimbrites}

The formation of ignimbrite deposits is a complex process that has significant impact on their mechanical properties. Key factors are 'welding'; glass transition temperature; and syn- and postcooling alteration processes. Welding refers to the syn- and post-depositional viscous deformation, fusion and compaction ('flattening') of glass shards, lapilli and pumice clasts, which post-compaction are known as fiamme (Grunder and Russell, 2005; Bull and McPhie, 2007). The welding process sinters and fuses particles together and decreases porosity, so that high degrees of welding (i.e. densely welded) correlate with increased unconfined compressive strength (Moon, 1993; Schultz and Li, 1995; Quane and Russell, 2005). The degree to which an ignimbrite is welded can be evaluated by measuring fiamme aspect ratio (Ragan and Sheridan, 1972; Kobberger and Schmincke, 1999). Fiamme in moderately-to-densely welded deposits have aspect ratios between 4 and 5 (Quane and Russell, 2005), these fiamme form a fabric of discontinuous layers, or eutaxitic texture, parallel or sub-parallel to the unit base. Poorly welded ignimbrites have fiamme aspect ratios less than 4 and a very poorly developed euxtaxitic texture.

The base of an ignimbrite is commonly marked by a vitrophyre, a massive fine-grained glassy layer formed by rapid cooling of the pyroclastic material. Generally, the vitrophyre is devitrified to a yellow, brittle, fine-grained powder (Ross and Smith, 1961). An ignimbrite may be composed of one or multiple ash-flows. If each ash-flow has been emplaced in rapid succession then the whole body of material will cool as a single cooling unit or layer (Smith et 1., 1994; Wilson et al., 2003). However, as the unit cools the level of welding compaction varies vertically and depends upon the duration over which the glassy shards and pumice remain viscous (Quane and Russell, 2005; Riehle et al., 2010). These vertical variations in welding describe the welding profile of an ignimbrite The ideal welding profile for a ignimbrite unit comprises a poorly welded (i.e. low density and high porosity) base and top, formed by rapid cooling and thus limited compaction. In the lower half of the unit, slower cooling permits high degrees of welding compaction (i.e. high density and low porosity) (Quane and Russel, 
2005 and references therein). In reality, a variety of ignimbrite welding profiles have been found including densely welded throughout (Henry and Wolff, 1992), densely welded lower half with a gradual decrease in compaction upward (Kobberger and Schmincke, 1999; Jutzeler et al., 2010) or multiple welding maxima and minima within the unit (Riehle et., 2010). The change between the welding facies is gradational. Commonly, the material at the top of the unit is increasingly ash rich and fiamme poor, recording the waning of the eruptive phase.

Deformation within an ignimbrite changes from ductile to brittle as cooling proceeds. Once welding compaction ceases, thermal stresses are relieved by the formation of columnar cooling joints (DeGraff and Aydin, 1993; Kobberger and Schmincke, 1999; Goehring and Morris, 2008; Sewell et al., 2012). The temperature at which this ductile-brittle transition occurs is known as the glass transition temperature $\left(\mathrm{T}_{g}\right)$, (Giordano et al., 2005) and demarcates the cooling front within the layer. The time taken for a deposit to cool below $\mathrm{T}_{\mathrm{g}}$ depends on several factors including the composition and initial temperature of the pyroclastic flow, flow layer thickness and substrate temperature (Ragan and Sheridan, 1972; Riehle, 1973; Miller and Riehle, 1994). For example, Riehle (1973) calculated that a $10 \mathrm{~m}$-thick rhyolitic pyroclastic flow will cool to half its initial temperature within 2 years while a $40 \mathrm{~m}$ thick layer requires 20 years.

Cooling joints initiate at the top and bottom of the unit and follow the cooling front toward the unit interior, forming elongate, regularly and spaced, polygonal columns with $\sim 120$ angles between joints (Goehring and Morris, 2008). Joint advancement is incremental, alternating between brittle joint propagation behind the cooling front and termination in the plastic medium beyond the cooling front. Consequently, the cooling joint surface is composed of sub-horizontal smooth (brittle) and rough (plastic) sections creating undulations or stria on the joint surface (Goehring and Morris, 2008). Mineralisation or alteration on or immediately around the cooling joint surface may also occur (Dunne et al., 2003).

Syn- and post-cooling secondary alteration processes can further alter the material properties of the ignimbrite. Vapour phase crystallisation precipitates minerals from hot gases, filling pore spaces in the ash matrix or pumice vesicles. Crystals grow discretely or as meshworks (McArthur et al., 1998), thus strengthening the matrix by reducing pore space and growth of interlocking crystals. Vapour phase alteration breaks down the glassy fiamme material to form either discrete acicular crystals growing inward from the fiamme rim or spherical intergrowths of elongate fibres called spherulites (Smith et al., 1994) within the fiamme.

The ignimbrite formation process significantly affects mechanical properties, and in particular, the spatial heterogeneity of rock strength. Welding has the capability to form discrete mechanical layers 
within the ignimbrite unit, although the gradational changes between facies may inhibit this outcome. The presence of fiamme, as well as the positions of secondary alteration processes may result in isolated mechanical heterogeneities within the ignimbrite that may perturb the local stress field sufficiently to serve as the nucleation points (i.e., flaws) for joint initiation. Cooling may create additional joints that increases overall joint abundance in a unit, reducing median joint spacing, and locally altering the joint spacing distributions.

\section{Geological setting}

The study area is located in the southwest of the caldera island of Gran Canaria, Spain (Fig. 1a). Initial caldera collapse occurred at $14 \mathrm{Ma}$, forming the ca. $20 \mathrm{~km}$ in diameter Tejeda caldera, and blanketing the island with at least 20 individual ignimbrite flows between $5 \mathrm{~m}$ to $40 \mathrm{~m}$ thick (Schminke, 2004; Jutzeler et al., 2010; Soden and Shipton, 2013). We focus on one of these ignimbrite units called ignimbrite B (Schmincke, 1998), which was erupted during initial caldera collapse and forms part of the Upper Mogan Formation (Fig. 1b). Ignimbrite B is a densely welded, ash and fiamme rich ignimbrite, blanketing the west and south of the island and ranging in thickness from 10-30 $\mathrm{m}$.

Coincident with caldera collapse and ignimbrite eruption was the formation of a system of extracaldera faults (Troll et al., 2002) and fractures (Soden and Shipton, 2013). Faults accommodating extension during caldera collapse formed parallel to the caldera margin (Fig. 1a), inflation of the caldera during subsequent eruptive cycles reactivated these faults and formed an additional set of faults radial to the caldera margin (Branney 1995; Walter and Troll, 2001; Holohan et al, 2012). Joint sets observed by Soden and Shipton (2013), both associated and unassociated with faults, display the same parallel and radial orientations relative to the caldera margin.

\section{Study site and data collection}

Data were collected from a $12 \mathrm{~m}$ thick cross-section of ignimbrite B exposed along a valley side at Los Frailes (Fig. 2a). Ignimbrite B is a single cooling unit with a basal vitrophyre marking the lower contact with ignimbrite $\mathrm{A}$ and the basal vitrophyre of ignimbrite $\mathrm{C}$ marking the top of the unit. Though fiamme rich throughout, the top 2 meters of Ignimbrite B is fiamme poor and ash rich, the long axes of fiamme are sub-parallel to the unit base. Along a path that runs form the base of ignimbrite B to 2 meters below the top of the unit, we collected fiamme data from five clean vertical faces that are exposed along road cuts. We collected no fiamme data between the road cuts as rock surfaces are heavily weathered, obscuring the fiamme. Joint data were collected along the entire length of the path, with the exception of one section where the surface was completely scree-covered (Fig. $2 a \& b)$. Each 
road-cut face is labelled $\mathrm{F}$ and numbered from 0 to 4 , where 0 is at the base of the unit and 4 at the top (Fig.2a, b \& c). No faults were observed at, or in the vicinity of the study site.

Joint data (spacing, orientation, height, and aperture) were recorded using one scanline starting at the base of the unit (RHS of Fig. 2a \& c) and continuing upward along the path to $10.5 \mathrm{~m}$ above the unit base (LHS of Fig. 2a \& c). At the base of ignimbrite B, the scanline was positioned immediately above the basal vitrophyre (face F0, Fig. 2a) and continued along the path at the base of the outcrops. The scanline was parallel to the strike of the outcrop and, due to the gradual slope of the path, subhorizontal. Data from every joint that touched or crossed the scanline was collected. All joints were observed to continue upward from the path, and the majority cut the entire height of the outcrop face, although some terminated within the face. For the total of 106 joints, the location and measured height of each was plotted against distance along the line (Fig. 2c). The use of a continuous scanline ensures the data are not biased by site selection on the best exposed faces, as would potentially be the case for discrete scanlines. Rather, our method provides a complete record from the exposed portions of the joint system along the scanline. Given the lack of horizontal variation in ignimbrite composition and the absence of faults in or near the sample line, we believe that the scanline captures the vertical variation in joint development through this one ignimbrite unit.

Joint spacing was recorded as the horizontal distance between all pairs of adjacent joints for which there was full exposure. The outcrop orientation changes along the path (Fig. 2b) and all joint spacing measurements have been corrected for strike using the Terzaghi correction. The mean strike values for the outcrop and the distance along the scanline along which they apply, starting at F0 and moving up along the path, are $075(0-4.5 \mathrm{~m}), 140(4.5 \mathrm{~m}-14.5 \mathrm{~m}), 014(14.5 \mathrm{~m}-33 \mathrm{~m}), 040(33 \mathrm{~m}-52 \mathrm{~m}), 035$ $(65 \mathrm{~m}-76 \mathrm{~m}), 077(76 \mathrm{~m}-84 \mathrm{~m}), 010(84 \mathrm{~m}-97 \mathrm{~m})$ and $075(100 \mathrm{~m}-106 \mathrm{~m})$. Joint dip ranges between $58^{\circ}$ and $90^{\circ}$ with a mean of $85^{\circ}$. Joint height was measured from the base of the unit or path to the joint tip or the top of the exposure. Nowhere was both the lower and upper end of a joint observed, thus measurements only constrain the minimum joint length at the exposure and are censored. On Face F0, all joints met the base of the unit, whereas on faces F1-F4 the lower end of the joints were not observed. No joints were observed to continue from ignimbrite $\mathrm{B}$ into either ignimbrite A or C, therefore ignimbrite $\mathrm{B}$ is considered to be an independently fractured mechanical unit.

The fiamme within the layer were sampled using $25 \times 25 \mathrm{~cm}$ squares drawn on to the vertical road-cut faces, as these provided the best exposure. Since the mechanical controls on joint initiation, propagation and termination were the focus of this study, the sample areas at each face were located where joint(s) were present. An example of a sample square, showing an annotated joint and neighbouring fiamme is shown in Figure 3. The number of sample squares on each face depended on the quality of the exposure, whereas both the fiamme and joints cutting the face, had to be clearly 
visible. Face 0, 1 and 2 have three sample squares and fiamme on Face 3 were sampled using two squares. Due to the poor quality of the exposure and small number of joints at Face 4, only one sample square was located on the face. The location of each sample square is shown in Figure 2a with white squares. Photographs of the sample areas were digitised, and using Image $\mathrm{J}$ freeware, the maximum and minimum axis of each fiamme and number of fiamme were recorded. The calculated fiamme aspect ratios were used to determine the degree of welding and any relative change in welding along a vertical profile through ignimbrite B. Fiamme that were totally or partially enclosed within the area of the sample square were measured in our analysis.

\section{Field data and analysis}

\subsection{Joint geometry}

The joints are steeply dipping having a mean dip of $85^{\circ}$, and orientated perpendicular to the unit base. Vertical trace length ranges from $2.5 \mathrm{~cm}$ to $3.8 \mathrm{~m}$ (Fig. 2c), although the maximum observed trace length was limited by the tops of the outcrop faces at any sampling location. The majority of joints have apertures of 2-3 mm, and the maximum aperture recorded was $3.7 \mathrm{~cm}$. No observed joints were mineralised. Joints are composed of planar sections that step where the joint intersects fiamme, as no joint surface was exposed, no plumose structures if present were observed. Consequently, we could not determine sites of joint initiation or the propagation paths.

Cluster analysis of the joint orientations (Stereonet 9.5, Allmendinger et al., 2012) reveals a well defined NW-SE joint set with an average strike of 127 , concentric to the caldera perimeter, and a less well defined NE-SW joint set with an average strike of 046, radial to the caldera margin (Fig. 4). Small populations of other joints have even weaker N-S and ENE-WSW trends. As mentioned previously, caldera collapse formed a system of extra-caldera faults and joints parallel and concentric to the caldera margin. At Los Frailes, the abundant NW-SE joint set is essentially parallel to the caldera margin. While there is greater scatter in the NE-SW joints, the mean orientation is perpendicular to the caldera margin, with a number of joints that are oblique to the margin.

We believe that one of two mechanisms could be responsible for joint formation: cooling and layerparallel extension related to caldera collapse. Distinguishing cooling joints from tectonic joints in ignimbrites is difficult in the absence of alteration products such as joint fill or bleached rims, which are attributes associated with cooling joints (Sweetkind et al., 2003). Furthermore, cooling joints can form decades after ignimbrite emplacement as the deposit cools to ambient temperatures (Dunne et al., 2003). None of the observed joints in ignimbrite B are mineralised, thus our assessment relies on joint geometrical properties. Several lines of evidence suggest that these joints formed in response to regional tectonic stresses after cooling. First, joint intersection angles and orientations are incompatible 
with a cooling origin. Rather than the $120^{\circ}$ that is common for intersecting cooling joints (Goehring and Morris, 2008), the intersection angle between the mean strike of the two sets we observed is $82^{\circ}$. Furthermore, the angle of intersections between adjacent joints is predominantly less than $50^{\circ}$ (Fig. 5), as opposed to the expected intersection angles of around $120^{\circ}$ or $60^{\circ}$ for cooling joints. Second, many joints exhibit geometrical interactions with fiamme, where joints step across fiamme (Fig. 6a, b \& d) and a number of joints terminate against horizontal or steeply dipping joints (Dunne et al., 2003). Hence, the joints interacted with these pre-existing features, rather than following a cooling front. Thirdly, joint spacing increases and correspondingly, joint abundance decreases toward the top of Ignimbrite B (Fig. 2d). This geometric pattern is contrary to the expectation for joints formed in response to thermal contraction, where joint spacing increases toward the layer centre (DeGraf and Aydin, 1993). Lastly, Soden and Shipton (2013) showed that joints in Ignimbrite B on the west coast of Gran Canaria are orientated NS and EW, radial and tangential to the caldera margin, respectively and formed in response to cycles of caldera inflation and collapse. In summary, evidence from analysis of the joint network geometry strongly suggests that the joints are not the result of cooling, but rather related to layer-parallel extension during caldera collapse and/or inflation..

\subsection{Joint intensity}

The scanlines record data obliquely upwards through the unit (Fig. 2c). We use these data to examine variation in joint characteristics from the base to the top of the layer, given the lack of nearby faults or lateral variation in ignimbrite composition to trigger changes in joint system attributes. To assess changes in joint frequency vertically within the unit, we plot the height within the unit against the horizontal spacing for each adjacent pair of joints with full exposure (Fig. 2d). Height is calculated as the height above the ignimbrite base mid-way between the pair of joints. This graph shows joints higher in the unit are more widely spaced and with greater variability in joint spacing, upward in the unit.

Joints in Ignimbrite B are layer confined and, given the relationship to the caldera margin, we suggest formed by layer extension during periods of caldera deflation and inflation. As previously stated, layer-confined, opening-mode joints commonly have a positive correlation between median joint spacing and mechanical layer thickness. The fundamental mechanism proposed to explain this relationship is the shear-lag model (Cox, 1952; Hobbs, 1967). Briefly the model involves the layerparallel extension of a competent layer bounded between two less competent layers. Joints form when the tensile stress exceeds the tensile strength of the competent layer, with sequential joints forming midway between existing joints when the tensile stress again exceeds the layer tensile strength. The shear-lag model predicts that continued layer-parallel extension will ultimately result in the fracturing layer becoming joint saturated; at this point no new joints will form regardless of increasing strain (Wu 
and Pollard, 1995; Bai et al, 2000; Bai and Pollard, 2000b; Dharani et al., 2003). Bai and Pollard (2000) proposed that a joint saturated layer will have a joint density (D) times layer thickness (T) between 0.8 and 1.2. If DT is approximately one, the layer is considered to be joint saturated, DT values $>1.2$ and $<0.8$ indicate the layer is over- and under-saturated respectively, and in the case of over-saturation new joints will not form by layer extension alone.

Already we have shown that joint spacing varies within the ignimbrite layer. To compare the joint intensity within the ignimbrite layer with studies in sedimentary rocks, we use the relationship between joint density (D) and layer thickness (T) (Ladeira and Price, 1981; Becker and Gross, 1996; Underwood et al., 2003). To estimate DT for the whole ignimbrite layer, we calculated the mean number of joints per meter, D, as 1.02 (Fig. 2d). This value yields a DT value for the whole $12 \mathrm{~m}$-thick ignimbrite B layer of 12.24. Indicating that, as a single mechanical layer, Ignimbrite B is highly joint over-saturated, which is contrary to Ladeira and Price (1981), who observed lower than expected joint intensity in thick layers.

\subsection{Fiamme mechanical properties}

Although the ignimbrite is densely welded throughout, a number of observations suggest that the fiamme are weaker than the ash matrix. Firstly, the ash matrix is pervasively jointed at the study site, whereas only one fiamme has joints that only occur in the fiamme without entering the adjacent welded ash. Secondly, SEM examination (Fig. 7) shows that the ignimbrite has undergone vapour phase alteration, producing meshworks of interlocking micro-crystals in the ash, thereby reducing porosity and strengthening the matrix (Fig. 7) (McArthur et al., 1998). Conversely, vapour phase alteration created porosity in fiamme, as well as producing discrete acicular crystals lining fiamme in the base of the unit and meshworks (spheurlites) of crystals in fiamme toward the top of the unit (Fig. 8). Although the exact timing of the secondary alteration relative to joint formation is uncertain, vapour-phase alteration occurs below the glass transition temperature when deformation changes from ductile to brittle (Giordano et al., 2005), thus the secondary alteration is either prior to or contemporaneous with jointing. The contrast in mechanical properties between the fiamme and ash will tend to promote joint initiation at the weaker fiamme, where a local tangential tensile stress is generated within the stiffer ash matrix (Pollard and Aydin, 1988).

\subsection{Distribution of fiamme}

Fiamme sampling squares $25 \times 25 \mathrm{~cm}$ were placed at heights of $0.25 \mathrm{~m}, 1.5 \mathrm{~m}, 5.5 \mathrm{~m}, 8.5 \mathrm{~m}$ and $10 \mathrm{~m}$ above the ignimbrite base for each of faces F0 through to F4, respectively (Fig. 2a). The fiamme density (\# fiamme $/ \mathrm{cm}^{2}$ ) for each face is plotted against height above the unit base in figure $8 \mathrm{a}$. A slight drop in fiamme abundance within the ignimbrite between station F1 and F2 is observed (Fig. 8a). The decrease in mean fiamme abundance (Fig. 8a) appears to coincide with the increase in mean joint 
spacing (Fig. 2d), which we suggest indicates weaker fiamme are localising tensile stress and 298 promoting joint initiation and propagation.

\subsection{Fiamme shape}

The welding profile of Ignimbrite B was examined by measuring the aspect ratio of each fiamme within the sample squares, from which the median aspect ratio for each face, as well as for the entire ignimbrite layer, were determined. The median fiamme aspect ratio for Ignimbrite B is 5.5, with values from each sample square ranging from 1.5 to 43 (Fig. 8b), thus Ignimbrite B is a densely welded ignimbrite (Quane and Russell, 2005). As with fiamme abundance, the fiamme aspect ratio decreases between station F1 and F2 (Fig. 8b), including the median, upper and lower quartiles of the aspect ratio distribution. Also, all but two of the measured fiamme with an aspect ratio greater than 20 are in the bottom 2 meters of the unit (Figure 8b). In section 2, we stated that a decrease in fiamme aspect ratio indicates a decrease in the degree of welding, hence welding intensity decreases toward the top of Ignimbrite B. The decrease in fiamme aspect ratio also coincides with the decrease in joint abundance (Fig. 2d). Lower aspect ratio fiamme are less oblate and, in cross-section, fiamme tips have a lower curvature. We suggest that the decrease in tip curvature diminishes the stress concentration tangential to the fiamme, thereby inhibiting joint propagation in the upper portion of Ignimbrite B.

\subsection{Joint-fiamme interaction}

From our analysis of the joint and fiamme data, we believe that the shape, material properties and distribution of the fiamme strongly influence joint initiation and propagation within Ignimbrite B. To investigate the potential role that fiamme shape had on joint propagation, we divided the fiamme data into two groups - jointed fiamme (i.e. those where a joint steps across, cross-cuts or terminates at the fiamme) and unjointed fiamme. A plot of these data shows that fiamme with greater aspect ratios are more commonly intersected by a joint (Fig. 8c). The results of a t-test demonstrate that at all stratigraphic positions, a highly significant difference exists between the mean aspect ratio of the jointed and unjointed fiamme, implying that joints intersect high-aspect ratio fiamme preferentially to lower aspect-ratio fiamme (Table 1).

\section{Insert Table 1}

Aspect ratio is a measure of fiamme compaction and hence potentially correlates with their mechanical properties. We must consider, however, the possibility that high aspect-ratio fiamme merely have a greater lateral extent, and consequently propagating joints have a greater probability of intersecting them. Data to discount this possibility are shown in Table 2, where the median lengths of jointed and unjointed fiamme differ by less than a millimetre but jointed fiamme aspect ratio is on average $40 \%$ greater than that of the unjointed fiamme. Hence, the observed preferential joint interaction with high 
aspect ratio fiamme is not due to an increase in their average lateral extent. Thus, the presence of fiamme with greater aspect ratios was an important contributor to joint initiation and propagation, by localising stress at fiamme tips. To further test this hypothesis, we analysed the different joint-fiamme interaction geometries, and positions along the length of fiamme where the joint intersected. (Table 3, Figure 6).

\section{Insert Table 2}

Four types of joint-fiamme interaction are observed (Fig.6): unlinked stepping joints and linked stepping joints that step across fiamme (Fig. $6 a \&$ b), single joints that pass straight through fiamme (Fig. 6c), and single joint tips located at fiamme, i.e. joint initiation or termination (Fig. 6b). All joints are orthogonal to the fiamme long axis. Importantly, as joint surfaces are unexposed and initiation points and propagation paths unknown, joint geometries reflect joint interactions with fiamme. Consequently, the observed joint tips may be a $2 \mathrm{D}$ section through a joint tip-line rather than the actual joint initiation or termination point. The location of the joints along the fiamme long axis was defined as either occurring at the fiamme tip or non-tip, where we defined the tip area as the distance from the fiamme tip to one quarter way along the length of the fiamme.

The results of the joint-fiamme interation analysis are shown in Table 3. For all faces, greater than $50 \%$ of all joint types intersect the tip area of the fiamme - F0 57.7\%; F1 55.5\%; F2 56\%; F3 60.2\%; F4 76\%. This supports our proposition that the high curvature fiamme tips localise tensile stress resulting in joint initiation and propagation. The remainder of the joints intersect the central portion of the fiamme, and hence, we infer that tangential stress resulting from a weak inclusion imbedded in a stronger matrix also has a role to play in joint propagation.

The joint geometries also reflect differences in material properties between the fiamme and ash matrix. The geometry of a joint is affected by the mechanical properties of the material through which it propagates. Work examining the propagation of joints in alternating shale and siltstone sequences (Hegelson and Aydin, 1991) demonstrates how the stress ahead of a joint tip is transmitted between stiff layers (higher modulus) across a weaker (lower modulus) interlayer. As the joint approaches the weaker interlayer, the transfer of the fracture tip stress across the layer produces two stress maxima in the unjointed stiff layer, which result in the joint stepping as it crosses the weaker layer. However, there is a critical weak layer thickness that impedes joint propagation, causing joints to terminate at the weak layer (Rijken and Cooke, 2001). When layers have similar Young's moduli the joint propagates straight through all layers.

In general, models of joint interaction with layer interfaces show joints often terminate at weak interfaces (Renshaw and Pollard, 1995; Cooke et al., 2006), propagate straight through strong 
interfaces, and step at interfaces of moderate strength (Cooke et al., 2006). Hence, the observed joint geometries reflect the variation in the relative strength between the fiamme and ash matrix, as well as the different fiamme-ash interface mechanical strengths. Between 58\% and $84 \%$ of joints cut straight through fiamme (Table 3), suggesting that either the fiamme and matrix are of the similar strength, or there is a strong fiamme-matrix interface. The greater proportion of these straight joints cut the fiamme tip, indicating a difference in material property between the fiamme and ash, as is shown by our SEM analysis. Further, the fiamme in this group have high aspect ratios indicating a strong degree of compaction and welding. Hence, the geometry is likely a result of a strong fiamme-ash interface. The next most frequently observed joint type are joint tips located at fiamme, however as we have stated, these may not be true joint tips and without seeing the joint surface we cannot say if these are joint initiation or termination points. It should be noted, however, that the lower tip of a joint is never observed (they all propagate down to the path or layer base). Hence, it seems likely that many observations of joint tips are terminations of upwardly propagating joints. In which case, given that the mean fiamme aspect ratios of this group do not differ greatly to fiamme in the other two groups, these fiamme must be much weaker than the ash matrix. As such, the weak fiamme are acting to terminate joints and hence reduce the joint intensity in the upper part of the ignimbrite. Stepping joints make up between $7 \%$ and $15 \%$ of all joint types and are approximately evenly split between joints intersecting fiamme at tips and non-tips. Joints stepping across fiamme indicate the fiamme are weaker than the matrix. We divided stepping joints into joints that are linked across fiamme via a horizontal section and those that are not linked (Table 3, Fig. 6b). The mean aspect ratio of fiamme in the unlinked stepping group is generally smaller than for fiamme cut by straight joints. Smaller aspect ratio indicates less compaction and welding and possibly a fiamme-ash interface of moderate strength. Fiamme in the linked stepping joint group have mean aspect ratios less than or similar to fiamme cut by straight joints. The latter case may reflect fiamme which having undergone vapour phase alteration and are weaker than the matrix.

\section{Insert Table 3}

The observations summarised in Table 3 support the proposition that fiamme perturbed the stress field during joint formation. The extent to which the stress field was perturbed, is a function of fiamme shape and the contrast in material properties between the fiamme and the surrounding matrix. For all joint geometry types, the greater proportion of joints interact with fiamme tips, thus the high curvature of the fiamme tips localise stress and are sites of joint initiation or propagation. The termination or stepping of joints is a result of the contrast in mechanical properties between fiamme and ash and the strength of the fiamme-ash interface. Given the competing effects of fiamme distribution, shape and material properties that influence the joint network, it is unlikely that small changes in any one 
parameter can be directly correlated to changes in joint intensity. Rather changes across all fiamme characteristics act to produce a greater change in joint intensity.

\section{Model for joint network development}

Based on our analysis, we believe that the control on joint intensity within Ignimbrite B is the spatial distribution, geometry and mechanical properties of the fiamme in the unit rather than the thickness of the unit. Joint intensity is greatest where the fiamme aspect ratio is greatest at the unit base. We propose this relationship is due to larger stress concentrations at the tips of the more elongate fiamme, which are weaker than the surrounding ash matrix, and to stress tangential to the weaker fiamme embedded in the stiffer matrix; providing favourable sites for joint nucleation (Fig. 9). If a joint approaches a densely welded fiamme, propagation straight through or with a step across the fiamme is likely, depending on the fiamme-ash mechanical contrast and the fiamme-ash interface strength. If a joint encounters a less welded, low aspect ratio fiamme it is more likely to terminate. We propose that joints propagate upward, and as they propagate upward they, encounter progressively fewer and less welded fiamme, thereby inhibiting joint propagation. This proposed model of joint initiation and growth (Fig. 9) explains the observed spatial distribution of joints throughout ignimbrite B, as well as the apparent decrease in joint intensity with increasing elevation within the unit.

Our analysis shows that the mechanical heterogeneity within Ignimbrite B plays a significant role in controlling joint geometry and location. The spatial distribution, mechanical and geometric properties of fiamme influence joint initiation, propagation and termination, which in turn control the abundance of joints throughout the unit. These results suggest that greater attention should be paid to the spatial heterogeneity of rock strength when developing predictive models for fracture networks. The properties and distribution of flaws like fiamme may exert controls on fracture network properties that are equal to or greater than the well-known influences of variables such as layer thickness and interfacial shear strength..

\section{Conclusions}

We study joint frequency and orientation throughout the full thickness of an ignimbite located on the island of Gran Canaria, Spain. Our observations show that joint spacing varies vertically within the unit, in tandem with subtle variations in the geometrical and mechanical properties of fiamme within the ash matrix. Propagating joints interact with fiamme and we propose that this interaction is responsible for the observed joint distribution and joint geometries. We propose a model whereby joint initiation, propagation and termination are governed by vertical variations in the geometrical and mechanical properties of the fiamme. We suggest that joints initiate near the base of the unit where the fiamme are more densely welded, due both to their high aspect ratio that causes larger stress 
concentrations at their tips, and their lower strength, which contrasts with the stronger surrounding ash matrix. Once initiated, we propose that joints propagate predominantly upwards through the unit. As they encounter fiamme, they either step across them or terminate. Joints are more likely to terminate on fiamme with low aspect ratios, which are more common in the upper half of the ignimbrite unit. As a result joint intensity is very high at the base of the unit and decreases with increasing elevation.

Our research shows that in a mechanically heterogeneous lithology (i.e. with inclusions, lenses, clasts etc.) with weakly defined layering, joint intensity can be governed by the number and spatial distribution of heterogeneities with particular geometrical and mechanical properties. Consequently, joint spacing and location in siliciclastic or volcaniclastic lithologies at depth, may not be well described by models based only on the role of layer thickness. More accurate predictions may require characterisation of the composition and material properties within each layer.

\section{References}

Allmendinger, R.W., Cardozo, N., Fisher, D.M., 2011. Structural Geology Algorithms: Vectors and Tensors. Cambridge University Press. ISBN: 9781107401389.

Bai, T., Pollard, D.D., 2000. Fracture spacing in layered rocks: a new explanation based on the stress transition: Journal of Structural Geology, v. 22, p. 43-57.

Bai, T., Pollard, D.P., 2000. Closely spaced fractures in layered rocks: initiation mechanism and propagation kinematics. Journal of Structural Geology, v. 22, p. 1409-1425.

Becker, A., Gross, M.R., 1996. Mechanism for joint saturation in mechanically layered rocks: an example from southern Israel: Tectonophysics, v. 257, p. 223-237.

Branney, M.J., 1995. Downsag and extension at calderas: new perspectives on collapse geometries from ice-melt, mining, and volcanic subsidence: Bulletin of Volcanology, v. 57, p. 303-318.

Brown, D.J., 2007. A guide to the use of volcaniclastic nomenclature in engineering investigations. Quaterly Journal of Engineering Geology and Hydrogeology 40, 105-112.

Bull, K.F., McPhie, J., 2007. Fiamme textures in volcanic successions: flaming issues of definition and interpretation. Journal of Volcanology and Geothermal Research 164, 205-216.

Cacas, M.C., Daniel, J.M., Letouzey, J., 2001. Nested geological modelling of naturally fractured reservoirs. Petroleum Geoscience 7, 543-552.

Cooke, M. L., J. A. Simo, C. A. Underwood, and P. Rijken, 2006, Mechanical stratigraphic controls on fracture patterns within carbonates and implications for groundwater flow: Sedimentary Geology, v. 184 , no. 3-4, p. 225-239.

Cox, H.L., 1952. The elasticity and strength of paper and other fibrous materials. British Journal of Aplied Physics 3, 72-79.

DeGraff, J.M., Aydin, A. 1987. Surface morphology of columnar joints and its significance to mechanics and direction of joint growth. Geological Society of America 99, 605-617.

Dharani, L.R., Wei, J., Ji, F.S., Zhao, J.H., 2003. Saturation of transverse cracking with delamination in polymer cross-ply composite laminates. International Journal of Damage Mechanics 12, 89-113 
Dunne, W.M., Ferrill, D.A., Crider, J.G., Hill, B., La Femina, P., Waiting, D., Morris, A.P., Fedors, R., 2003. Orthogonal jointing during coeval igneous degassing and normal faulting, Yucca Mountain, Nevada. Geological Society of America Bulletin 115, 1492-1509.

Fischer, M.P., Polansky, A., 2006. Influence of flaws on joint spacing and saturation: Results of onedimensional mechanical modelling. Journal of Geophysical Research, 111. B07403, doi: 10.10292005JB004115.

Fox, D. B., Sutter, D., Beckers, K. F., Lukawski, M. Z., Koch, D., Anderson, B. J., Tester, J. W., 2013. Sustainable heat farming: Modeling extraction and recovery in discretely fractured geothermal reservoirs. Geothermics 46, 42-54.

Giordano, D., Nichols, A.R.L., and Dingwell, D.B., 2005. Glass transition temperatures of natural hydrous melts: a relationship with shear viscosity and implications for the welding process. Journal of Volcanology and Geothermal Research 142, 105-118.

Goehring, L., Morris, S. W., 2008. Scaliing of columnar joints in basalt. Journal of Geophysical Research B113, B10203.

Gross, M.R., 1993. The origin and spacing of cross joints: examples from the Monterey Formation, Santa Barbara Coastline, California: Journal of Structural Geology 15, 737-751.

Gross, M.R., Engelder, T., 1995. Strain accommodated by brittle failure in adjacent units of the Monterey Formation, U.S.A.: scale effects and evidence for uniform displacement boundary conditions: Journal of Structural Geology 17, 1303-1318.

Grunder, A., Russell, J.K., 2005. Welding processes in volcanology: insights from field, experimental, and modeling studies: Journal of Volcanology and Geothermal Research, Welding Processes in Volcanology 142, 1-9.

Helgeson, D.E., Aydin, A., 1991. Characteristics of joint propagation across layer interfaces in sedimentary rocks. Journal of Structural Geology 13, 897-911.

Henry, C.D., Wolff, J.A., 1992. Distinguishing strongly rheomorphic tuffs from extensive silicic lavas. Bulletin of Volcanology 54, 171-186.

Hobbs, D.W., 1967. The formation of tension joints in sedimentary rocks: an explanation. Geological Magazine, v. 104, p. 550-556.

Hoek, E., Brown, E. T., 1997. Practical estimates of rock mass strength. Int. J. Rock. Min. Sci. 34, 1165-1186.

Hofmann, H., Babadagli, T., Zimmermann, G., 2014. Hot water generation for oil sands processing from enhanced geothermal systems: Process simulation for different hydraulic scenarios. Applied Energy 113, 524-547.

Holohan, E., Schöpfer, M. P. J., Walsh, J. J., 2011. Mechanical and geometric controls on the structural evolution of pit crater and caldera subsidence. Journal of Geophysical Research, 116, B07

Huang, Q., Angelier, J., 1989. Fracture spacing and its relation to bed thickness. Geological Magazine, 104, 355-362.

Ji, S., Saruwatari, K., 1998. A revised model for the relationship between joint spacing and layer thickness: Journal of Structural Geology, 20, 1495-1508.

Jimenez-Martinez, J., Longuevergne, L., Borgne, T., Davy, P., Russian, A., Bour, O., 2013. Temporal and spatial scaling of hydraulic response to recharge in fractures aquifers: Insights from a frequency domain analysis. Water Resources Research 49, 3007-3023. 
Jutzeler, M., Schmincke, H-U., Sumita, M., 2010. The incrementally zoned Miocene Ayagaures ignimbrite (Gran Canaria, Canary Islands). Journal of Volcanology and Geothermal Research 196, 119.

Kobberger, G., Schmincke, H.-U., 1999. Deposition of rheomorphic ignimbrite D (Mogan Formation), Gran Canaria, Canary Islands, Spain: Bulletin of Volcanology, 60, 465-485.

Koning, T., 2003. Oil and gas production from basement reservoirs: Examples from Indonesia, USA and Venezuela. In: Petford N., McCaffrey K.J.W.(eds) Hydrocarbons in Crystalline Rocks. Geological Society, London, Special Publications 214, 83-92.

Ladeira, F. L., N. J. Price, 1981. Relationship between fracture spacing and bed thickness. Journal of Structural Geology 3, 179-183.

Larsen, B., Gudmundsson, A., Grunnaleite, I., Saelen, G., Talbot, M.R., and Buckley, S.J., 2010.

Effects of sedimentary interfaces on fracture pattern, linkage, and cluster formation in peritidal carbonate rocks. Marine and Petroleum Geology 27, 1531 - 1550.

McArthur, A.N., Cas, R.A.F., and Orton, G.J., 1998. Distribution and significance of crystalline, perlitic and vesicular textures in the Ordovician Garth Tuff (Wales). Bulletin of Volcanology 60, 260285.

McConaughy, D.T., Engelder, T., 2001. Joint initiation in bedded clastic rocks. Journal of Structural Geology 23, 203-221.

Miller, T. F., Riehle, J. R., 1994. A users manual for Ashpac: a program for predicting cooling, outgassing and compaction of pyroclastic deposits. Tech. Rep. TR94-14, Applied Research Lab., Penn. State Univ., State College.

Moon, V. G., 1993. Geotechnical characteristics of ignimbrite: A soft pyroclastic rock type, Eng. Geol., v. 35, p. 33-45.

Neuman, S. P., 2005. Trends, prospects and challenges in quantifying flow and transport through fractured rocks. Hydrogeology journal 13, 124-147.

Narr, W., Suppe, J., 1991. Joint spacing in sedimentary rocks: Journal of Structural Geology 13, 10371048.

Pollard, D.D., Aydin, A., 1988. Progress in understanding jointing over the past century: Geological Society of America Bulletin 100, 1181-1204.

Quane, S.L., Russell, J.K., 2003. Ranking welding intensity in pyroclastic deposits. Bulletin of Volcanology 67, 129-143.

Ragan, D.M., Sheridan, M.F., 1972. Compaction of the Bishop tuff, California. Geological Society of America Bulletin 83, 95-106.

Renshaw, C.E., Pollard, D.D., 1994. Numerical simulation of fracture set formation: A fracture mechanics model consistent with experimental observations: Journal of Geophysical Research 99, 9359-9372.

Riehle, J. R., 1973. Calculated compaction profiles of Rhyolitic ash-flow tuffs. Geological Society of America Bulletin 84, 2193-2216.

Riehle, J. R., Miller, T. F., Paquereau-Lebti, P., 2010. Compaction profiles of ash-flow tuffs: Modeling versus reality. Journal of Volcanology and Geothermal Research 195, 106-120.

Rijken, P., Cooke, M. L., 2001. Role of shale thickness on vertical connectivity of fractures: application of crack-bridging theory to the Austin Chalk, Texas. Tectonophysics 337, 117-133. 
Ross, C.S., Smith, R.L. 1961. Ash-flow tuffs; their origin, geologic relations and identification. U.S. geol. Survey Prof. Paper 366, 1-77

Schmincke, H.U., 1998. Geological Field Guide to Gran Canaria. Pluto Press, Kiel.

Schultz, R.A., Li, Q., 1995. Uniaxial strength testing of non-welded Calico Hills tuff, Yucca Mountain, Nevada: Engineering Geology, v. 40, p. 287-299.

Sewell, R.J., Tang, D. L. K., Diarmad, S., and Campbell, D. G., 2012. Volcanic-plutonic connections in a tilted nested caldera complex in Hong Kong. Geochem. Geophys. Geosyst. 13, Q01006.

Smith, J.V., Yamauchi, S., Miyake, Y., 1994. Coaxial progressive deformation textures in extrusive and shallow intrusive rocks, southwest Japan. Journal of Structural Geology 16, 315-322.

Soden, A. M., Shipton, Z. K., 2013. Dilational fault zone architecture in a welded ignimbrite: The importance of mechanical stratigraphy. Journal of Structural Geology 51, 156-166.

Troll, V., Walter, T., Schmincke, H.U., 2002. Cyclic caldera collapse: Piston or piecemeal subsidence? Field and experimental evidence. Geology 30, 135-138.

Tuckwell, G.W., Lonergan, W.L., Jolly, R.H.J., 2003. The control of stress histroy and flaw distribution on the evolution of polygonal fracture networks. Journal of Structural Geology 25, 1241 1250 .

Underwood, C.A., Cooke, M.L., Simo, J.A., Muldoon, M.A., 2003. Stratigraphic controls on vertical fracture patterns in Silurain dolomite, northeastern Wisconsin. AAPG Bulletin 87, 121-142.

Walter, T.R., Troll, V.R., 2001. Formation of caldera periphery faults: an experimental Study. Bulletin of Volcanology 63, 191-203.

Weinberger, R., 2001a. Joint nucleation in layered rocks with non-uniform distribution of Cavities. Journal of Structural Geology 23, 1241-1254.

Weinberger, R., 2001b. Evolution of polygonal patterns in stratified mud during dessication: The role of flaw distribution and layer boundaries. Geological Society of America Bulletin 113, 20 - 31.

Wilson, J.E., Goodwin, L.B., Lewis, C.J., 2003. Deformation bands in nonwelded ignimbrites: petrophysical controls on fault-zone deformation and evidence of preferential fluid flow. Geology 31 , 837-840.

Wu, H., Pollard, D., 1995. An experimental study of the relationship between joint spacing and layer thickness. Journal of Structural Geology 17, 887-905.

\section{Figure Captions}

Figure 1: a) Location map of the study area at Los Frailes, the caldera perimeter and an extracaldera fault concentric to the caldera perimeter, also shown are the outcropping Mogan and Fataga Group volcanics (light grey) and shield basalt (dark grey). b) Simplified stratigraphy of the Miocence and Pliocene and volcanic phases and detailed stratigraphy of the Mogan Group which contains Ignimbrite $\mathrm{B}$, the focus of this study.

Figure 2: a) View of the exposure at Los Frailes which provides a complete cross-section through the $12 \mathrm{~m}$ thick Ignimbrite B unit. A path (grey line) runs from the base to the top of Ignimbrite B and five clean vertical faces (F0, F1, F2, F3 and F4) are accessible along the path. White square mark the location of the $25 \times 25 \mathrm{~cm}$ fiamme sample squares. b) The orientation of the vertical faces changes moving up through the unit, reducing any orientation sampling bias in the joint data. Start and end points of the scanline are marked X and X' respectively. c) Graph displays data for joint spacing and 
joint height (vertical length of grey line) moving up through the unit. d) Joint spacing (cm) vs height above unit base, height is the height of the mid-point between joint pairs.

Figure 3: Example of 25x25cm square from F1 enclosing a joint. Fiamme long axes are sub-horizontal, some fiamme are highlighted in white.

Figure 4: Stereonet data plotted for all joints measure along the scanline $(n=106)$. Great circles are for mean strike of NW-SE and NE-SW joint sets. Grey great circle is approximate caldera margin orientation relative to Los Frailes study site.

Figure 5: Angle of intersections between joints, and the frequency with which intersection angles occur.

Figure 6: Examples of the interaction between fiamme and joints from faces (F) at different heights in the ignimbrite. $a \& b$ ) On intersecting high aspect ratio fiamme, joints step across the fiamme (ringed in red) forming composite joints composed of multiple segments. c) Where fiamme are less compacted joints pass through the fiamme tips. d) Stepping of a joint along multiple fiamme gives a curved geometry to the joint.

Figure 7: Fiamme (selection outlined in red) and ash matrix a) $1 \mathrm{~m}$ and b) $6 \mathrm{~m}$ above the ignimbrite base. Fiamme in the base of the unit are compacted and elongate. Secondary alteration processes have devitrified the glassy fiamme and formed acicular crystals in fiamme at the base (c) and spherulites in fiamme in the upper section of the unit (d), as well as crystal meshworks within the matrix (e). The meshworks reduce porosity in the ash matrix. f) Even at the micron level fiamme influence joint geometry causing a joint to step across fiamme.

Figure 8: Plots show for each face (F) number of fiamme per square centimetre (a) and aspect ratio for all fiamme sampled within each sample square (b) and fiamme divided into jointed (JF) and unjointed (UNJF) fiamme (c). Sample size at each face for JF and UNJF respectively are F0 n=380 \& 220; F1 $n=311 \& 232 ; F 2$ n=219 \& 451; F3 n=151 \& 118; F4 n=66 \& 42. Note: Box plots in (c) are vertically offset for visual clarity but fiamme were sampled from the same squares on the outcrop, JF data are plotted at the actual sample heights.

Figure 9: Our model demonstrates how mechanical heterogeneities can have a significant impact on joint density within a layer, and that predictions of joint density based on layer thickness will differ greatly from the density and distribution of joints formed in a mechanically heterogeneous layer. Within the layer mechanical heterogeneities can i) localise tensile stress and initiate joints and ii) act as discontinuous mechanical sub-layers promoting or inhibiting joint propagation and influencing joint geometry. 


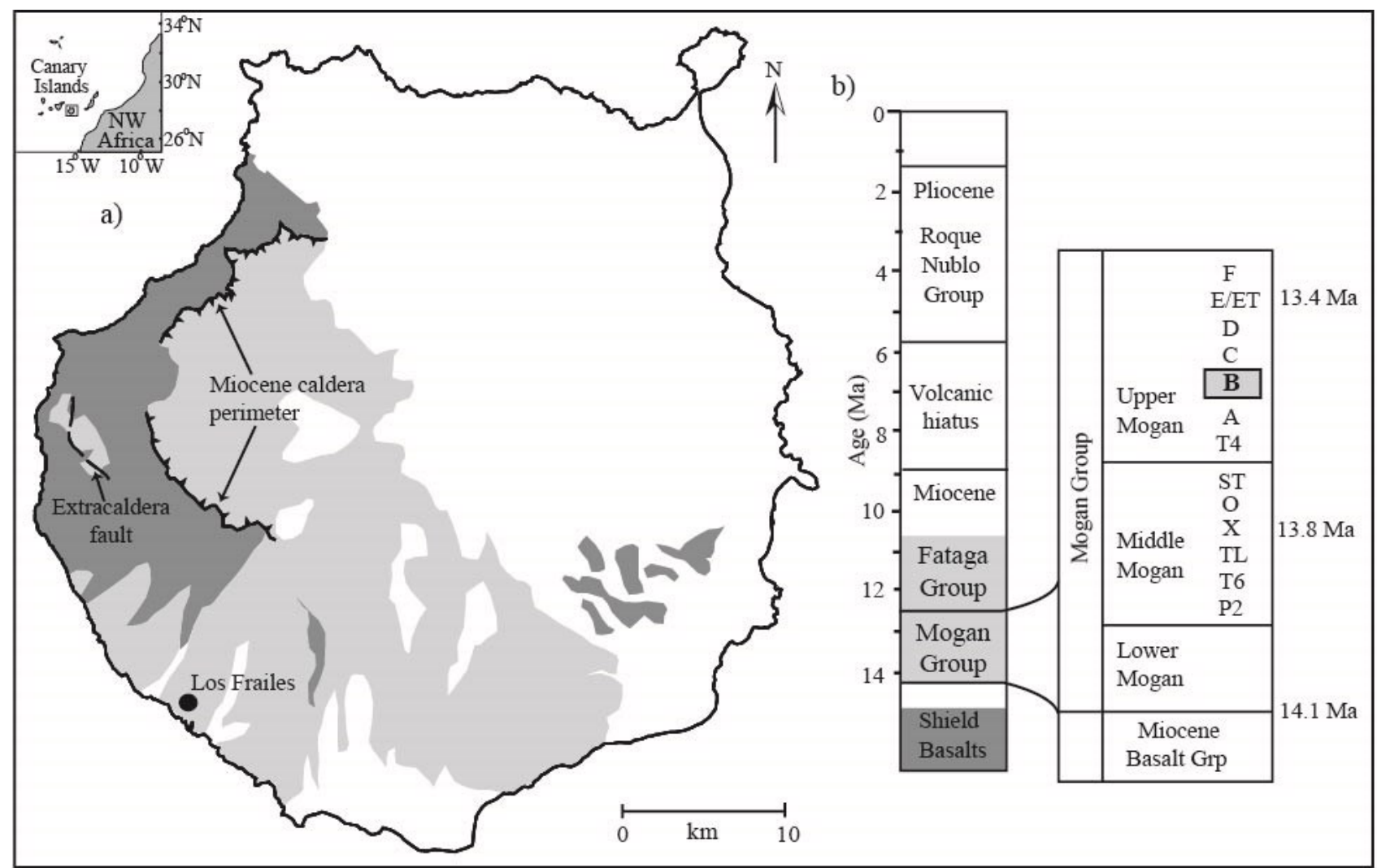

Figure 1: a) Location map of the study area at Los Frailes, the caldera perimeter and an extracaldera fault concentric to the caldera perimeter, also shown are the outcropping Mogan and Fataga Group volcanics (light grey) and shield basalt (dark grey). b) Simplified stratigraphy of the Miocence and Pliocene volcanic phases and detailed stratigraphy of the Mogan Group which contains Ignimbrite B, the focus of this study. 

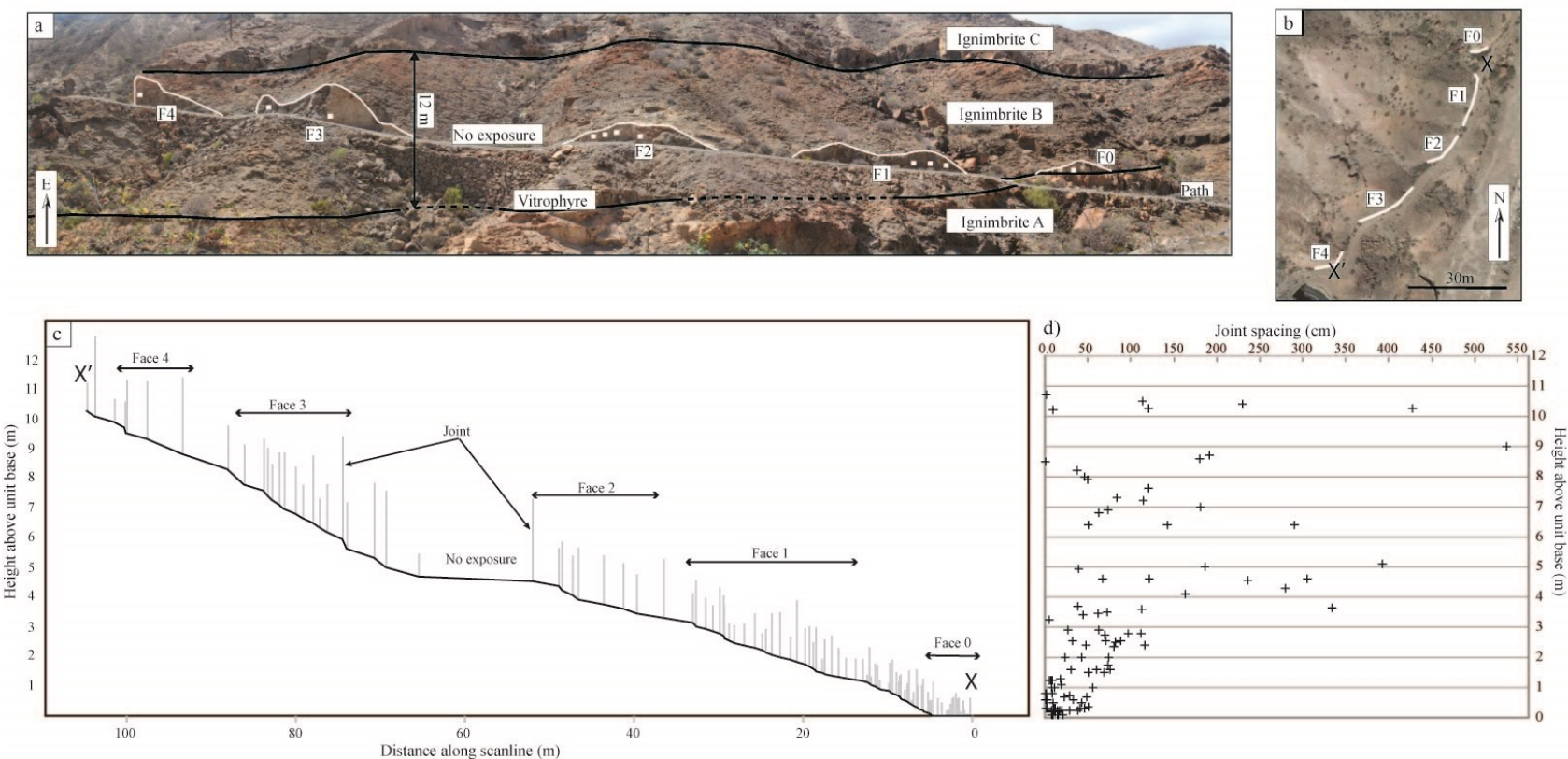

Figure 2: a) View of the exposure at Los Frailes which provides a complete cross-section through the $12 \mathrm{~m}$ thick Ignimbrite B unit. A path (grey line) runs from the base to the top of Ignimbrite B and five clean vertical faces (F0, F1, F2, F3 and F4) are accessible along the path. White square mark the location of the $25 \times 25 \mathrm{~cm}$ fiamme sample squares. b) The orientation of the vertical faces changes moving up through the unit, reducing any orientation sampling bias in the joint data. Start and end points of the scanline are marked $X$ and $X$ ' respectively. c) Graph displays data for joint spacing and joint height (vertical length of grey line) moving up through the unit. d) Joint spacing $(\mathrm{cm})$ vs height 637 above unit base, height is the height of the mid-point between joint pairs. 


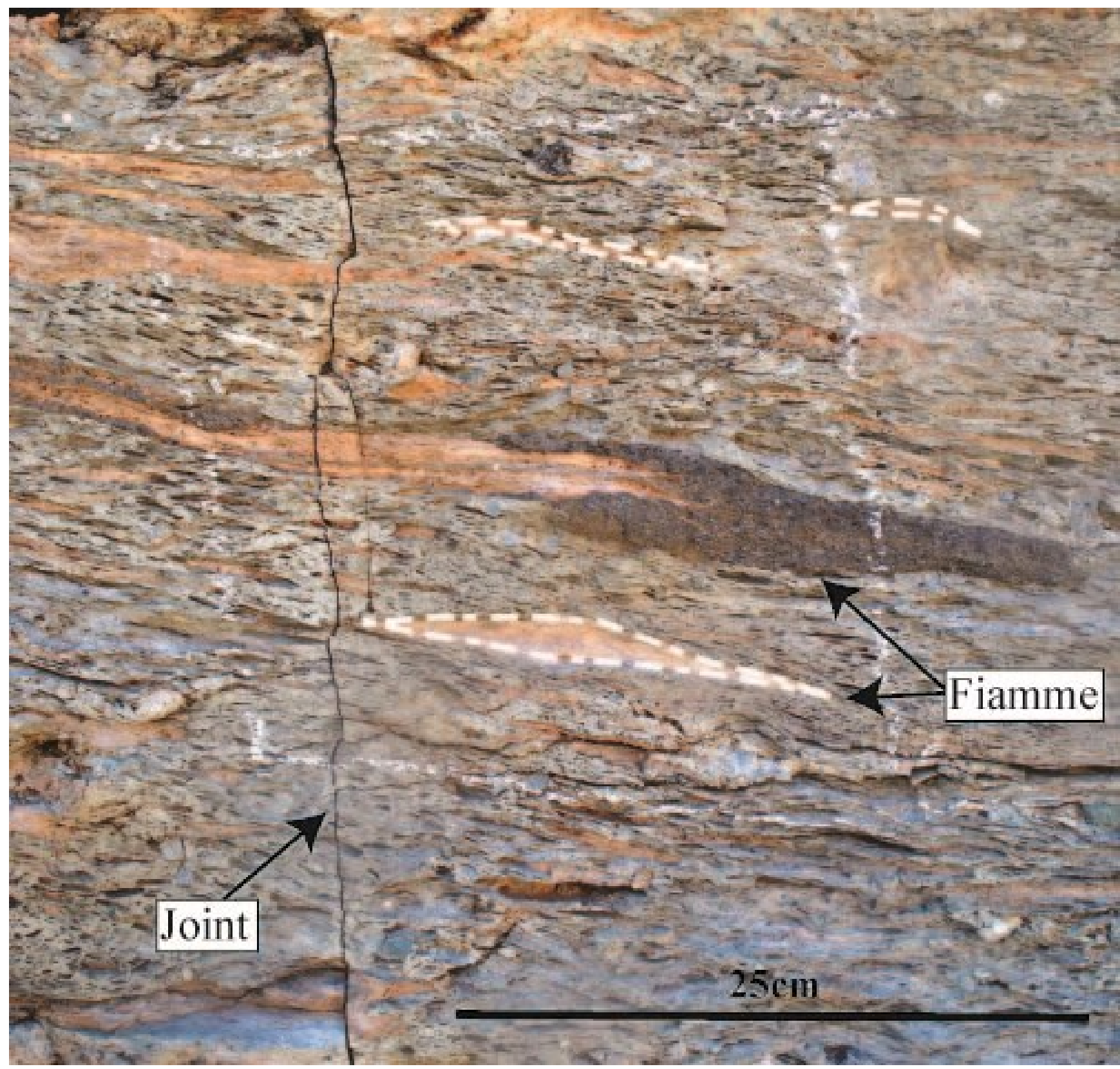

Figure 3: Example of $25 \times 25 \mathrm{~cm}$ square from F1 enclosing a joint. Fiamme long axes are sub-horizontal, some fiamme are highlighted in white. 


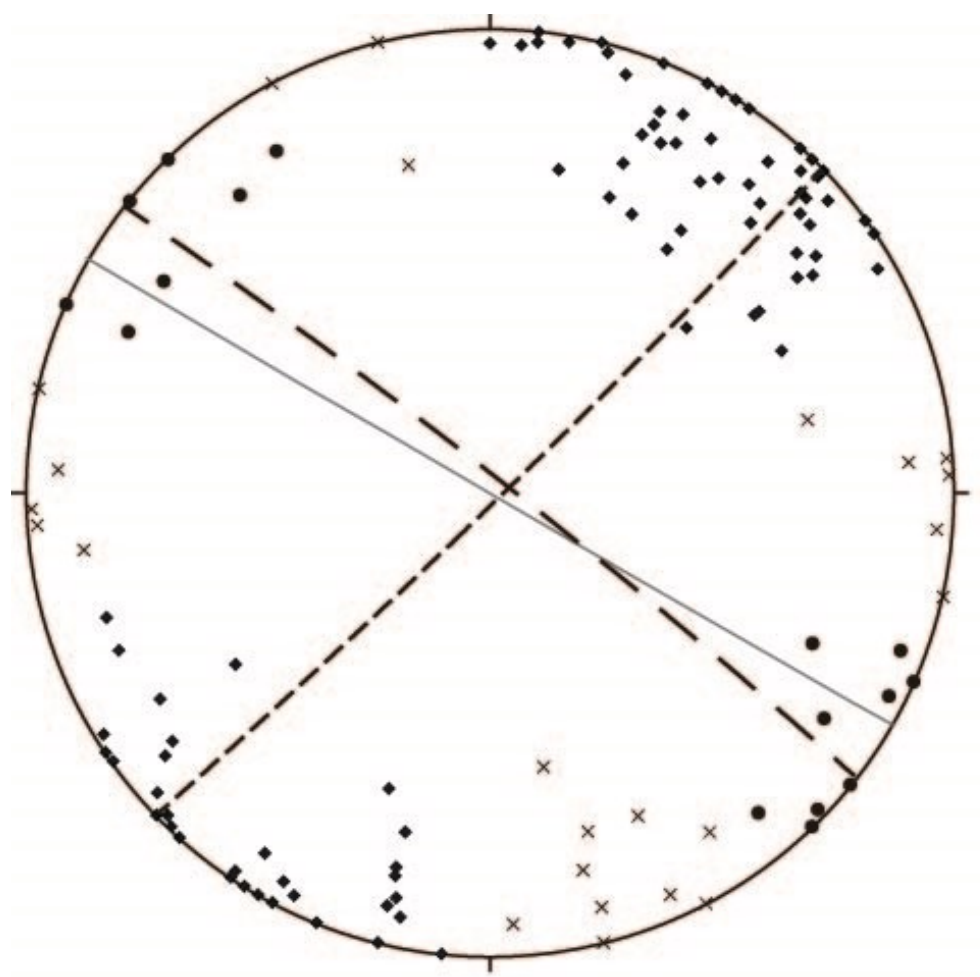

Fractures Mean strike

- NE-SW n=13 - - -

- NW-SE $\mathrm{n}=74-$ -

645

Figure 4: Stereonet data plotted for all joints measure along the scanline $(n=106)$. Great circles are for mean strike of NW-SE and NE-SW joint sets. Grey great circle is approximate caldera margin orientation relative to Los Frailes study site. 


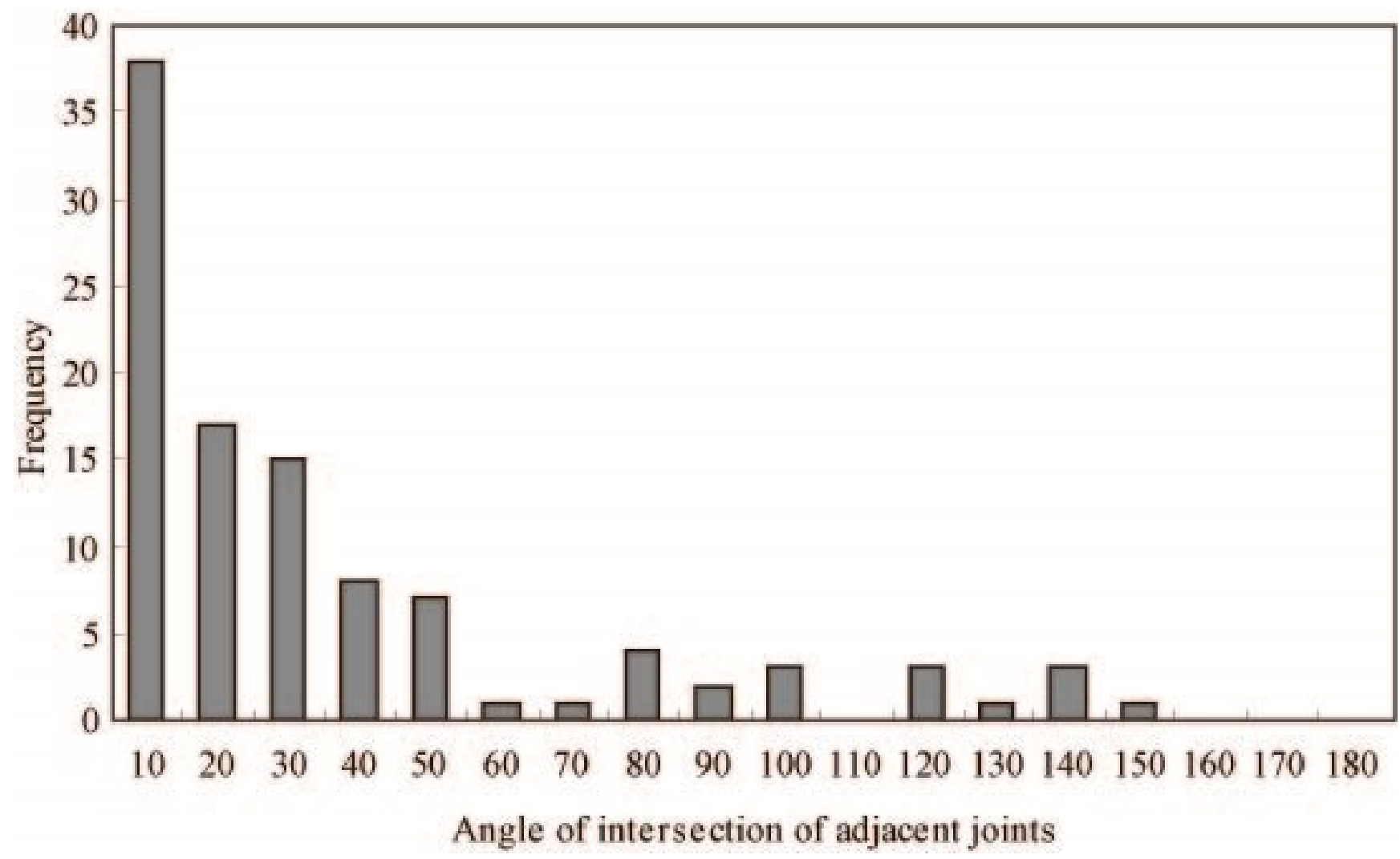

652

653 Figure 5: Angle of intersections between joints, and the frequency with which intersection angles 654 occur.

655 

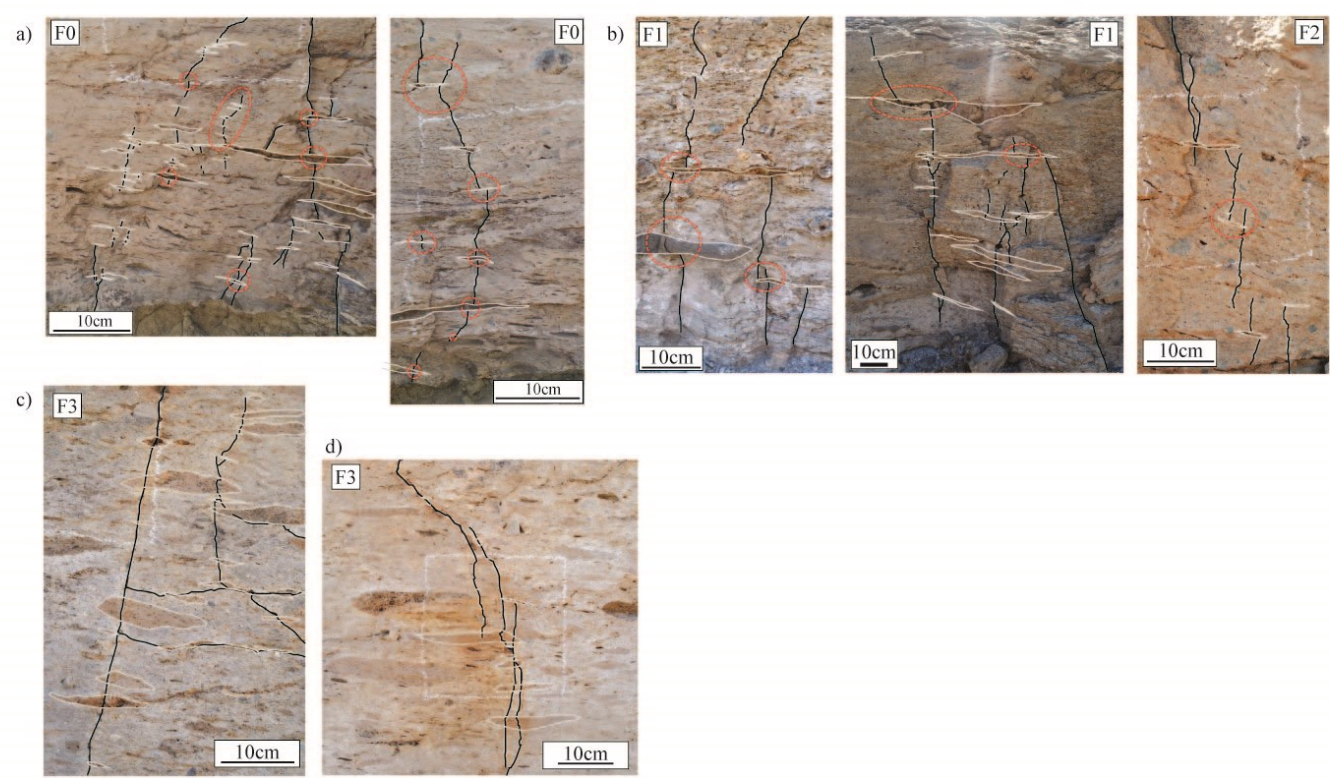

657 Figure 6: Examples of the interaction between fiamme and joints from faces (F) at different heights in the ignimbrite. a \& b) On intersecting high aspect ratio fiamme, joints step across the fiamme (ringed in red) forming composite joints composed of multiple segments. c) Where fiamme are less compacted joints pass through the fiamme tips. d) Stepping of a joint along multiple fiamme gives a curved 661 geometry to the joint. 

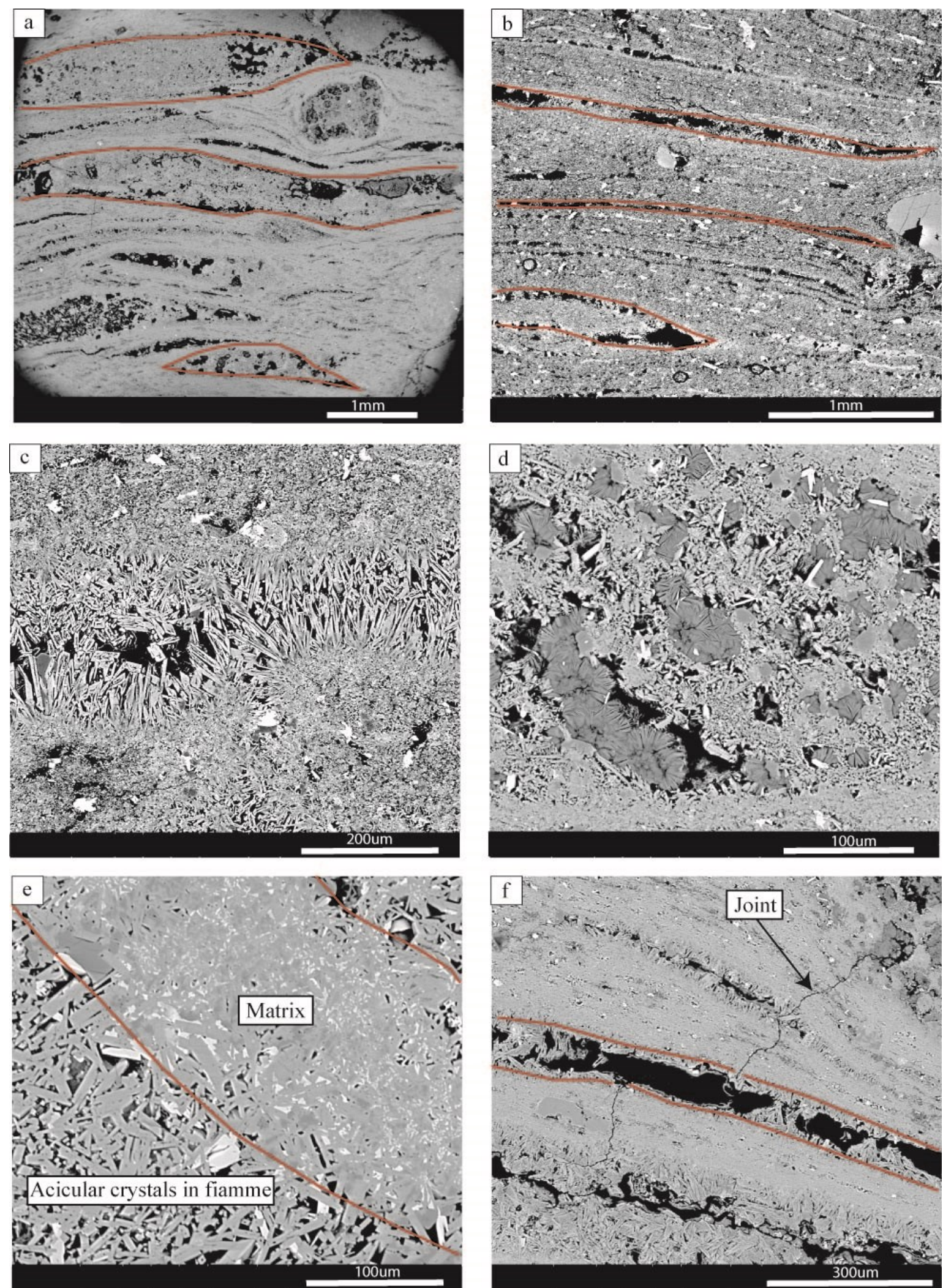

664

Figure 7: Fiamme (selection outlined in red) and ash matrix a) $1 \mathrm{~m}$ and b) $6 \mathrm{~m}$ above the ignimbrite base. Fiamme in the base of the unit are compacted and elongate. Secondary alteration processes have devitrified the glassy fiamme and formed acicular crystals in fiamme at the base (c) and spherulites in fiamme in the upper section of the unit (d), as well as crystal meshworks within the matrix (e). The meshworks reduce porosity in the ash matrix. f) Even at the micron level fiamme influence joint geometry causing a joint to step across fiamme. 

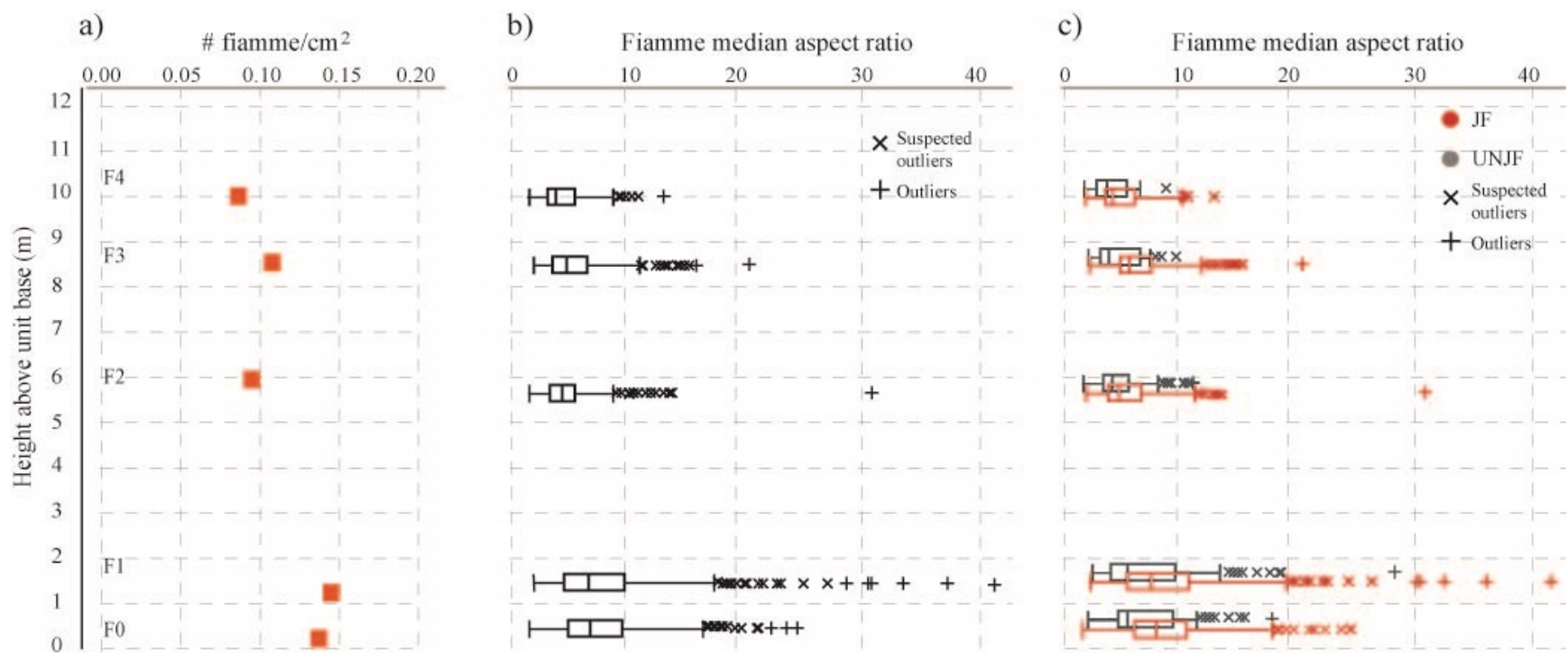

672 Figure 8: Plots show for each face $(\mathrm{F})$ number of fiamme per square centimetre (a) and aspect ratio for all fiamme sampled within each sample square (b) and fiamme divided into jointed (JF) and unjointed (UNJF) fiamme (c). Sample size at each face for JF and UNJF respectively are F0 n=380 \& 220; F1 $\mathrm{n}=311 \& 232 ; \mathrm{F} 2 \mathrm{n}=219 \& 451 ; \mathrm{F} 3 \mathrm{n}=151 \& 118 ; \mathrm{F} 4 \mathrm{n}=66$ \& 42. Note: Box plots in (c) are vertically offset for visual clarity but fiamme were sampled from the same squares on the outcrop, JF data are plotted at the actual sample heights. 


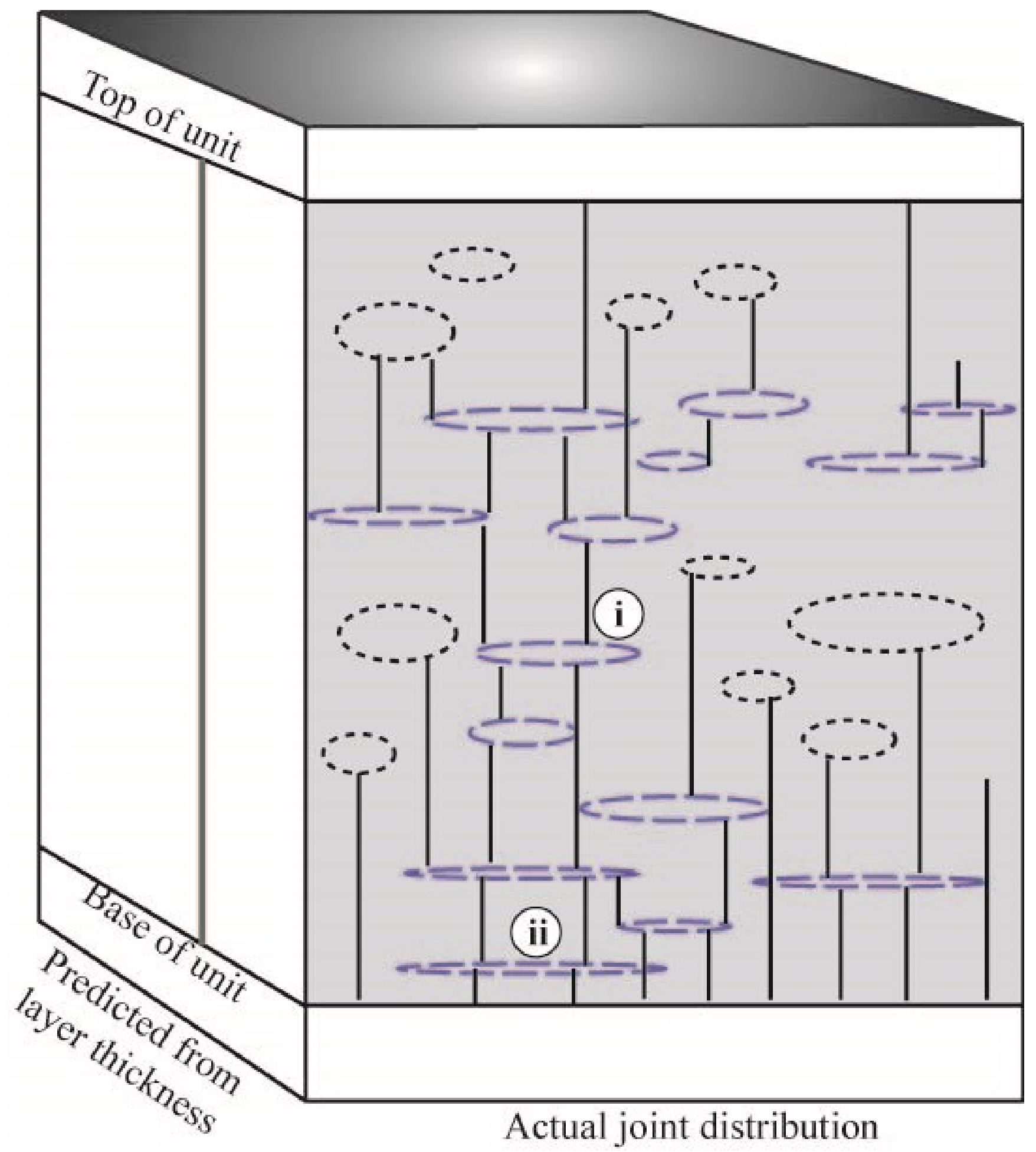

Figure 9: Our model demonstrates how mechanical heterogeneities can have a significant impact on joint density within a layer, and that predictions of joint density based on layer thickness will differ greatly from the density and distribution of joints formed in a mechanically heterogeneous layer. Within the layer mechanical heterogeneities can i) localise tensile stress and initiate joints and ii) act as discontinuous mechanical sub-layers promoting or inhibiting joint propagation and influencing joint geometry. 